\title{
Combustion Model of Supersonic Rocket Exhausts in an Entrained Flow Enclosure
}

\author{
Bruce $\mathrm{T} . \mathrm{Vu}^{1}$ and Justin Oliveira ${ }^{2}$ \\ NASA Kennedy Space Center, FL 32899 \\ Dimal Patel ${ }^{3}$ \\ Orbital Sciences Corporation, Inc., VA 20166
}

This paper describes the Computational Fluid Dynamics (CFD) model developed to simulate the supersonic rocket exhaust in an entrained flow cylinder. The model can be used to study the plume-induced environment due to static firing tests of the Taurus-II launch vehicle. The finite-rate chemistry is used to model the combustion process involving rocket propellant (RP-1) and liquid oxidizer (LOX). A similar chemical reacting model is also used to simulate the mixing of rocket plume and ambient air. The model provides detailed information on the gas concentration and other flow parameters within the enclosed region, thus allowing different operating scenarios to be examined in an efficient manner. It is shown that the real gas influence is significant and yields better agreement with the theory.

$\begin{array}{ll} & \\ \widetilde{A}_{k} & =\text { pre-exponential factor for reaction step } k \\ C_{i} & =\text { molar concentration of species } i \\ D & =\text { coefficient of diffusivity } \\ e & =\text { total energy per unit volume } \\ E_{A k} & =\text { activation energy of reaction step } k \\ f, g, h & =\text { fluxes in } x, y, z \text { directions } \\ \gamma & =\text { ratio of specific heats } \\ g_{i} & =\text { Gibbs free energy of species } i \\ K & =\text { coefficient of thermal conductivity } \\ K_{f k} & =\text { forward rate constant for reaction } k \\ K_{b k} & =\text { backward rate constant for reaction } k \\ \mu & =\text { first coefficient of viscosity } \\ \lambda & =\text { second coefficient of viscosity } \\ M_{i} & =\text { chemical symbol of species } i \\ N_{T} & =\text { exponent of temperature in the rate constant of reaction } k \\ q & =\text { dependent conservation variable } \\ R & =\text { gas constant } \\ R_{0} & =\text { universal gas constant } \\ \sigma & \text { turbulence transport quantities } \\ \rho & \end{array}$

\footnotetext{
${ }^{1}$ Lead, Fluid Systems Group, Senior Member AIAA.

2 Aerospace Engineer, Member AIAA.

${ }^{3}$ Principle Engineer, Guidance, Navigation, and Control Department.
}

1

American Institute of Aeronautics and Astronautics 


$\begin{array}{ll}S & =\text { source term } \\ T & =\text { static temperature } \\ \tau_{i j} & =\text { viscous stresses } \\ u, v, w & =\text { velocities in } x, y, z \text { directions } \\ \widetilde{W}_{i} & =\text { molecular weight of } i \\ v_{i k}^{\prime} & =\text { stoichiometric coefficient of } i \text { in reactant side of step } k \\ v_{i k}^{\prime \prime} & =\text { stoichiometric coefficient of } i \text { in product side of step } k \\ w_{i k} & =\text { mass flow rate per unit volume of production of } i \text { from reaction } k\end{array}$

\section{Introduction}

TASA awarded to Orbital Sciences Corperation (OSC) a Commercial Orbital Transportation Service (COTS) 1 contract to demonstrate delivery of cargo to the International Space Station. For these COTS missions OSC intends to use Taurus-II to launch its Cygnus spacecraft. The baseline Taurus-II is a two-stage vehicle, designed to launch payloads weighing up to $15,000 \mathrm{lbs}$ into low-Earth orbit (Figure 1). The first stage uses RP-1 (kerosene) and liquid oxygen (LOX) as propellants, powering two Aerojet AJ-26-62 main engines. The second stage is a CASTOR 30 solid rocket motor, built by Alliant Tech Systems, Inc. (ATK). This paper focuses on the first stage engine only. This engine is previously known as the Russian NK-33 liquid rocket engine, which provides high performance with light weight design, high chamber pressure, stable combustion, and a LOX rich preburner ${ }^{1}$. Currently OSC is planning to conduct a series of cold and hot first stage tests at Wallops Flight Facility (WFF). During these tests the two main rocket engines will be enclosed in an extended cylinder that resembles the hold-down bay. As shown in Figure 2, there are several vents around the cylinder to allow air entrainment during the hot firing test. The objective of this analysis is to solve the flowfield within the enclosed cylinder and to quantify the amount of air entrained during the test. The solutions can also be applied toward the study of the plume-induced environment. The analysis is based on multi-species, chemical reacting simulations. The results at the nozzle exit are compared to theoretical rocket performance data obtained from chemical equilibrium with applications (CEA) ${ }^{2}$. A simplified, single-species simulation is also presented here for comparison purposes

\section{Modeling Approach}

The analysis pertains to a complex system involving swirling flows, complex chemical reactions and complex geometry. These complexities provide a significant computational challenge. All modeling reported in this paper was performed using CFD++ 10.1, a multi-purpose CFD code developed by Metacomp Technologies, Inc., ${ }^{3,5}$.

A multi-block, structured mesh is created to model the AJ-26 rocket engines in an enclosed cylinder (Figure 3). There are a total of 321,936 cells for the single-species case and 406,656 cells for the multi-species case. In both cases a symmetry boundary condition is used to reduce the computational domain by half. The entire domain is initialized with a small disturbance $(V=0.01 \mathrm{~m} / \mathrm{s})$; this disturbance helps initialize the freestream turbulence quantities in the $\kappa-\varepsilon$ model.

The solution is based on compressible, real gas, Reynolds-Average Navier-Stokes (RANS) with a $\kappa-\varepsilon$ turbulence model. The simulation starts from the combustion chamber, where the total pressure and temperature are specified. For single species, ideal gas simulation only total conditions $(P=162 \mathrm{~atm}$ and $T=3814 \mathrm{~K})$ are required in the combustion chamber and the gas flow in the nozzle is assumed to be air with a constant specific heat ratio $(\gamma=1.4)$. For multi-species simulations the fuel-oxidizer reactions in the chamber and mixing reactions outside of the nozzle are also described in the boundary conditions. The three main chemical molecules that made up the fuel and oxidizer are carbon, hydrogen and oxygen. Outside of the nozzle, nitrogen is added to make up the ambient air. Combustion is handled using 11-species, 18-reaction chemistry mechanism solved with a finite-rate kinetics scheme and a constant-pressure combustion model. Standard non-reflecting, interpolated boundary conditions are imposed at the outflow boundary, as well as no-slip conditions at solid surfaces and symmetry boundary condition at the midplane. Steady-state solutions are obtained using a multi-grid, time-stepping scheme. The solutions are compared between single-species, non-reacting and multi-phase, finite-rate chemical reacting flows. The solutions are also compared against theoretical performance data obtained from CEA. 


\section{Governing Equations}

The CFD++ flow solver can be used to provide steady-state or unsteady flowfield solutions by solving the transport equations such as mass conservation equation, time averaged Navier-Stokes equations, energy equation and other scalar transport equations. The general form of these equations can be written as:

$$
\frac{\partial q}{\partial t}+\frac{\partial\left(f_{i}-f_{v}\right)}{\partial x}+\frac{\partial\left(g_{i}-g_{v}\right)}{\partial y}+\frac{\partial\left(h_{i}-h_{v}\right)}{\partial z}=S
$$

where the subscripts $i$ and $v$ denote the inviscid and viscous flow terms, respectively. For the Reynoldsaveraged Navier-Stokes equations the dependent quantities and the inviscid fluxes can be written as:

$$
q=\left(\begin{array}{c}
e \\
\rho \\
\rho u \\
\rho v \\
\rho w \\
\rho \sigma_{1} \\
\vdots \\
\rho \sigma_{N}
\end{array}\right)
$$

$$
f_{i}=\left(\begin{array}{c}
(e+p) u \\
\rho u \\
\rho u^{2}+p \\
\rho u v \\
\rho u w \\
\rho u \sigma_{1} \\
\vdots \\
\rho u \sigma_{N}
\end{array}\right)
$$$$
g_{i}=\left(\begin{array}{c}
(e+p) v \\
\rho v \\
\rho v u \\
\rho v^{2}+p \\
\rho v w \\
\rho v \sigma_{1} \\
\vdots \\
\rho v \sigma_{N}
\end{array}\right)
$$$$
h_{i}=\left(\begin{array}{c}
(e+p) w \\
\rho w \\
\rho w u \\
\rho w v \\
\rho w^{2}+p \\
\rho w \sigma_{1} \\
\vdots \\
\rho w \sigma_{N}
\end{array}\right)
$$

where $\sigma_{i}$ 's represent turbulence kinetic energy and "undamped" eddy viscosity in the pointwise turbulence models. Flow with multiple species can also be computed within this framework. The first five rows represent terms from the standard Euler equations with the first being the energy equation followed by the continuity and three momentum equations. The equation of state couples pressure to density and temperature is the perfect gas equation of state ( $p=\rho R T$ ) which can be written in terms of the conservation variables as follows:

$$
p=(\gamma-1)\left(e-\frac{1}{2 \rho}\left((\rho u)^{2}+(\rho v)^{2}+(\rho w)^{2}\right)\right)
$$

The viscous terms are defined as follows:

$f_{v}=\left(\begin{array}{c}K \frac{\partial T}{\partial x}+u \tau_{x x}+v \tau_{x y}+w \tau_{x z} \\ 0 \\ \tau_{x x} \\ \tau_{x y} \\ \tau_{x z} \\ \rho D \frac{\partial \sigma_{1}}{\partial x} \\ \vdots \\ \rho D \frac{\partial \sigma_{N}}{\partial x}\end{array}\right) \quad g_{v}\left(\begin{array}{c}K \frac{\partial T}{\partial y}+u \tau_{x y}+v \tau_{y y}+w \tau_{y z} \\ 0 \\ \tau_{x y} \\ \tau_{y y} \\ \tau_{y z} \\ \rho D \frac{\partial \sigma_{1}}{\partial y} \\ \vdots \\ \rho D \frac{\partial \sigma_{N}}{\partial z}\end{array}\right) \quad h_{v}=\left(\begin{array}{c}K \frac{\partial T}{\partial z}+u \tau_{x z}+v \tau_{y z}+w \tau_{z z} \\ 0 \\ \tau_{x z} \\ \tau_{y z} \\ \tau_{z z} \\ \rho D \frac{\partial \sigma_{1}}{\partial z} \\ \vdots \\ \rho D \frac{\partial \sigma_{N}}{\partial z}\end{array}\right)$

where viscous stresses $\tau_{i j}$ 's are defined as: 


$$
\begin{aligned}
& \tau_{x x}=2 \mu \frac{\partial u}{\partial x}-\frac{2}{3} \mu\left(\frac{\partial u}{\partial x}+\frac{\partial v}{\partial y}+\frac{\partial w}{\partial z}\right) \\
& \tau_{y y}=2 \mu \frac{\partial v}{\partial y}-\frac{2}{3} \mu\left(\frac{\partial u}{\partial x}+\frac{\partial v}{\partial y}+\frac{\partial w}{\partial z}\right) \\
& \tau_{z z}=2 \mu \frac{\partial w}{\partial z}-\frac{2}{3} \mu\left(\frac{\partial u}{\partial x}+\frac{\partial v}{\partial y}+\frac{\partial w}{\partial z}\right) \\
& \tau_{x y}=\mu\left(\frac{\partial u}{\partial y}+\frac{\partial v}{\partial x}\right) \quad \tau_{x z}=\mu\left(\frac{\partial u}{\partial z}+\frac{\partial w}{\partial x}\right) \quad \tau_{y z}=\mu\left(\frac{\partial v}{\partial z}+\frac{\partial w}{\partial y}\right)
\end{aligned}
$$

where the Stokes theorem for gases is assumed to hold true, thus $\lambda=\frac{2}{3} \mu$. The temperature can be related to the conservation quantities via the equation of state:

$$
T=\frac{p}{\rho R}=\frac{(\gamma-1)}{R}\left(\frac{e}{\rho}-\frac{(\rho u)^{2}+(\rho v)^{2}+(\rho w)^{2}}{2 \rho^{2}}\right)
$$

The source terms are written as:

$$
S=\left(\begin{array}{llllllll}
0 & 0 & g_{x} & g_{y} & g_{z} & \Omega_{1} & \cdots & \Omega_{N}
\end{array}\right)^{T}
$$

where $g_{i}$ 's are the body forces which can be activated if necessary, and $\Omega_{\mathrm{i}}$ 's are the source terms such as production and dissipation of turbulence.

\section{Chemistry Model}

Hydrocarbon rocket fuels such as RP-1 consist of at-least 87 identifiable hydrocarbon based compounds ${ }^{6,7}$. Modeling the reaction rates for each of these compounds in addition to the subset of possible intermediate compounds would result in a very large and, for the present study, unnecessary computational burden. Therefore the approach taken is to utilize the widely accepted wet- $\mathrm{CO}\left(\mathrm{H}_{2} \mathrm{O}\right.$ catalyzed) and thermal-NO mechanisms as described in the following sections, which model the thermophysics associated with conversion of the intermediate state compounds to their final combustion products. The initial global reaction steps to these intermediate molecular states are model as irreversible reactions of the RP-1 hydrocarbon chains with oxygen. The initial intermediate states in the combustion chamber are provided by the industry standard complex chemical equilibrium code $\mathrm{CEA}^{2}$.

In the present study, the finite-rate reactions of hydrogen, oxygen, and carbon are considered for the chemistry model in the combustion chamber. This model employs 8 species and 12 elementary reactions. Outside of the nozzle exit, nitrogen molecule is considered for the plume-air mixing reaction, which involves 3 more species and 6 more reactions. For a general chemical reaction $k$ :

$$
\sum_{i} v_{i k}^{\prime} M_{i} \rightleftharpoons \sum_{i} v_{i k}^{\prime \prime} M_{i}
$$

where the rate of production of species $i$ from the reaction step $k$ can be written as follows:

$$
\omega_{i k}=\widetilde{W}_{i}\left(v_{i k}^{\prime \prime}-v_{i k}^{\prime}\right)\left[K_{f k} \prod_{l} C_{l}^{v_{i k}^{\prime}}-K_{b k} \prod_{l} C_{l}^{v_{i k}^{\prime \prime}}\right]
$$

The forward rate constant for each reaction step $k$ is given by Arrhenius kinetics: 


$$
K_{f k}=\widetilde{A}_{k} T^{N_{T}} \exp \left(\frac{-E_{A_{k}}}{R_{o} T}\right)
$$

Any kinetic step, including reactions with third bodies in the product and/or reactant side can be included in the flow solver through inputs of $v_{i k}^{\prime}, v_{i k}^{\prime \prime}, A_{k}, N_{T}, N_{P}, E_{A k}$.

The backward rate constant $K_{b k}$ is computed from the equilibrium condition:

$$
\frac{K_{f k}}{K_{b k}}=\left(\frac{P_{a t m}}{R_{0} T}\right)^{\sum v_{i k}^{\prime \prime} \tilde{W}_{i} g_{i}} \exp \left(\frac{-\Delta \bar{G}_{k}}{R_{o} T}\right)
$$

where the change in Gibbs free energy for reaction step $k$ is given by:

$$
\Delta \bar{G}_{k}=\sum_{i=1}^{N} v_{i k}^{\prime \prime} \widetilde{W}_{i} g_{i}-\sum_{i=1}^{N} v_{i k}^{\prime} \widetilde{W}_{i} g_{i}
$$

A summary of chemical reactions and reaction rates used in the model is given in Table 1 . The first 12 reactions are related to RP-1 and LOX in the combustion chamber and the last 6 reactions describe the exhaust plume mixing with air outside of the rocket nozzle. These reaction equations are obtained from various sources ${ }^{8,9,10}$.

\begin{tabular}{|c|l|c|c|c|}
\hline & $K_{f k}=\widetilde{A}_{k} T^{N_{T}} \exp \left(\frac{-E_{A_{k}}}{R_{o} T}\right)$ & $\widetilde{A}_{k} \frac{1}{s}\left(\frac{\mathrm{cm}}{\mathrm{kmol}}\right)^{n-1}$ & $N_{T}$ & $E_{A_{k}}(\mathrm{~J} / \mathrm{kmol})$ \\
\hline 1 & $\mathrm{H}+\mathrm{O}_{2} \rightleftharpoons \mathrm{OH}+\mathrm{O}$ & $1.2 \times 10^{20}$ & -0.91 & 69156380 \\
\hline 2 & $\mathrm{H}_{2}+\mathrm{O} \rightleftharpoons \mathrm{OH}+\mathrm{H}$ & $1.5 \times 10^{10}$ & 2.00 & 31624892 \\
\hline 3 & $\mathrm{O}+\mathrm{H}_{2} \mathrm{O} \rightleftharpoons \mathrm{OH}+\mathrm{OH}$ & $1.5 \times 10^{12}$ & 1.14 & 72256999 \\
\hline 4 & $\mathrm{OH}+\mathrm{H}_{2} \rightleftharpoons \mathrm{H}_{2} \mathrm{O}+\mathrm{H}$ & $1.0 \times 10^{11}$ & 1.60 & 13810871 \\
\hline 5 & $\mathrm{O}+\mathrm{H}+\mathrm{M} \rightleftharpoons \mathrm{OH}+\mathrm{M}$ & $1.0 \times 10^{19}$ & 0.0 & 0 \\
\hline 6 & $\mathrm{O}+\mathrm{O}+\mathrm{M} \rightleftharpoons \mathrm{O}_{2}+\mathrm{M}$ & $1.0 \times 10^{20}$ & -1.0 & 0 \\
\hline 7 & $\mathrm{H}+\mathrm{H}+\mathrm{M} \rightleftharpoons \mathrm{H}_{2}+\mathrm{M}$ & $9.7 \times 10^{19}$ & -0.6 & 0 \\
\hline 8 & $\mathrm{H}_{2} \mathrm{O}+\mathrm{M} \rightleftharpoons \mathrm{H}+\mathrm{OH}+\mathrm{M}$ & $1.6 \times 10^{20}$ & 0.0 & 478375275 \\
\hline 9 & $\mathrm{O}_{2}+\mathrm{H}_{2} \rightleftharpoons \mathrm{H}+\mathrm{OH}+\mathrm{OH}$ & $7.9 \times 10^{17}$ & 0.0 & 187147514 \\
\hline 10 & $\mathrm{CO}+\mathrm{OH} \rightleftharpoons \mathrm{CO}+\mathrm{H}$ & $4.4 \times 10^{9}$ & 1.5 & -3102421 \\
\hline 11 & $\mathrm{CO}+\mathrm{O}+\mathrm{M} \rightleftharpoons \mathrm{CO}+\mathrm{M}$ & $5.3 \times 10^{16}$ & 0.0 & -19014967 \\
\hline 12 & $\mathrm{CO}+\mathrm{O}_{2} \rightleftharpoons \mathrm{CO}+\mathrm{O}$ & $2.5 \times 10^{15}$ & 0.0 & 200157545 \\
\hline 13 & $\mathrm{O}+\mathrm{N}_{2} \rightleftharpoons \mathrm{N}+\mathrm{NO}$ & $1.4 \times 10^{17}$ & 0.0 & 314117874 \\
\hline 14 & $\mathrm{~N}_{2}+\mathrm{O}_{2} \rightleftharpoons \mathrm{NO}+\mathrm{NO}$ & $9.4 \times 10^{27}$ & -2.5 & 537538443 \\
\hline 15 & $\mathrm{NO}+\mathrm{O} \rightleftharpoons \mathrm{N}+\mathrm{NO}$ & $1.6 \times 10^{12}$ & 1.0 & 161843947 \\
\hline 16 & $\mathrm{NO}+\mathrm{M} \rightleftharpoons \mathrm{O}+\mathrm{N}+\mathrm{M}$ & $2.3 \times 10^{20}$ & -0.5 & 623224476 \\
\hline 17 & $\mathrm{~N}+\mathrm{OH} \rightleftharpoons \mathrm{NO}+\mathrm{H}$ & $4.0 \times 10^{16}$ & 0 & 0 \\
\hline 18 & $\mathrm{CO}+\mathrm{N} \rightleftharpoons \mathrm{CO}+\mathrm{NO}$ & $2.0 \times 10^{14}$ & -0.5 & 33283891 \\
\hline
\end{tabular}

Table 1. Reaction Rate Equations

\section{Discussion of Results}

It is shown that for the non-reacting calculations, if the $\kappa-\varepsilon$ turbulence model is used, the swirl is predicted to decay too quickly and therefore recirculation zones are not captured. As a result, the single-species simulation shows a greater air entrainment at the ceiling, whereas in the multi-species simulation the recirculation causes flow 
reversals, thus reducing the entrainment from the top. Figures 4 and 5 show the velocity vectors at the symmetry plane for single-species and multi-species, respectively. Also, particle traces in Figures 6 and 7 indicate that a lower entrainment rate is detected for the multi-species case, due to recirculation and flow reversals.

Furthermore, the single-species simulation with constant specific heat ratio $(\gamma)$ shows an over-predicted solution at the nozzle exit plane. Figure 8 shows the Mach contours on the symmetry plane, where $M=6.83$ at the nozzle exit centerline; which is much higher than the CEA prediction $(M=3.667)$. The simple explanation is that the speed of sound is a function of specific heat ratio and molecular weight or singularly local static temperature. What is expected to be occurring in reality is additional energy release from continued exothermic reaction in the nozzle, most notably the re-combination of dissociated molecules of hydrogen and oxygen from the now changing equilibrium conditions as the flow expands and reduces static pressure and temperatures in the nozzle. This is clearly evident in Fig 9 which depicts a sharp increase in total temperature of the flow as the flow expands past the throat of nozzle for the reacting chemistry case and matches well with CEA predictions.

For single-species, ideal gas simulation, both of these parameters are assumed to be constant, resulting in a low speed of sound compared to real gas. Figure 10 shows the speed of sound contours for the ideal gas simulation, where $c=384.84 \mathrm{~m} / \mathrm{s}$ at the nozzle exit centerline, compared to $c=879.4 \mathrm{~m} / \mathrm{s}$ predicted by CEA. The underprediction by the ideal gas assumption can also be found from observing other flow parameters, e.g. pressure and temperature at the nozzle exit centerline are predicted to be $0.0458 \mathrm{~atm}$ and $368.13 \mathrm{~K}$, respectively. CEA yields at the same location a pressure of $0.664 \mathrm{~atm}$ and temperature of $2041.12 \mathrm{~K}$. Figures 11 and 12 show the pressure and temperature contours at the symmetry plane. These results are sound in the sense that it correctly predicted the shock structures in the plume flowfield ${ }^{11}$, but the under-prediction of pressure magnitude makes the nozzle more over-expanded that it actually is.

The multi-species simulation with finite-rate chemistry shows a much better agreement with the theory. Figures 13-16 show the contours for Mach number, sonic velocity, pressure, and temperature at the symmetry plane. The conditions at the nozzle exit plane obtained from these simulations match up with CEA within $1 \%$ of error. In addition, Figures 17-21 show the mole fractions of some of the gases that made up the plume and ambient air. Apparently, there are strong recirculation zones between the plumes and in the region between the cylinder and external nozzle surface. These behaviors were not captured in the single-phase, ideal gas simulation. Table 2 summarizes the nozzle exit plane conditions, predicted by CEA and by real gas simulation. Excellent agreement has been achieved with the current chemistry model.

\begin{tabular}{|l|l|l|l|l|}
\hline FLOW VARIABLES & Chamber & Throat & $\begin{array}{l}\text { Exit } \\
\text { (CEA) }\end{array}$ & $\begin{array}{l}\text { Exit } \\
\text { (CFD++) }\end{array}$ \\
\hline $\mathrm{P}, \mathrm{atm}$ & 162.02 & 93.541 & 0.66433 & 0.65199 \\
\hline $\mathrm{T}, \mathrm{K}$ & 3814.03 & 3617.25 & 2041.12 & 2041.24 \\
\hline Sonic velocity, $\mathrm{m} / \mathrm{s}$ & 1224.2 & 1182.2 & 879.4 & 883.7 \\
\hline Mach number & 0.0 & 1.0 & 3.695 & 3.669 \\
\hline MOLE FRACTION & \multicolumn{5}{|l}{} \\
\hline $\mathrm{CO}$ & 0.29698 & 0.28981 & 0.23532 & 0.23511 \\
\hline $\mathrm{CO} 2$ & 0.16922 & 0.18276 & 0.27071 & 0.27078 \\
\hline $\mathrm{H}$ & 0.02327 & 0.02030 & 0.00072 & 0.00072 \\
\hline $\mathrm{H} 2$ & 0.06879 & 0.06675 & 0.07650 & 0.07689 \\
\hline $\mathrm{H} 2 \mathrm{O}$ & 0.34094 & 0.35551 & 0.41627 & 0.41570 \\
\hline $\mathrm{O}$ & 0.01191 & 0.00925 & 0.00000 & 0.00000 \\
\hline $\mathrm{OH}$ & 0.06620 & 0.05660 & 0.00048 & 0.00043 \\
\hline $\mathrm{O} 2$ & 0.02238 & 0.01885 & 0.00001 & 0.00001 \\
\hline
\end{tabular}

Table 2. AJ-26 Combustion Data

\section{Conclusion}

Calculations were performed on a dual nozzle, RP-1/LOX combustion engine as part of an ongoing effort to study the plume-induced environment due to stage testing of Taurus-II launch vehicle. It has been shown that the finite-rate chemistry impacted the computational results. When included in the computational model, the chemical reaction significantly influences the flowfield. While the non-reacting, single-species simulation can provide

6

American Institute of Aeronautics and Astronautics 
quantitative results, it cannot capture all physical features of this particular problem. The plume flowfield obtained from this model can be used to improve the thermal analysis that determines the plume impingement impact on ground support equipment.

\section{Acknowledgments}

The authors would like to acknowledge Mr. John Morin and Ms. Marina Browning from Orbital Sciences Corporation for their technical insights. Thanks are also due to Mr. Steven Cain and the NASA Commercial Crew Planning Office for the support of this collaboration..

\section{References}

1. Lacefield, T.C. and Sprow, W.J., "High Performance Russian NK-33 LOX/kerosene Liquid Rocket Engine," AIAA-1994$3397,30^{\text {th }}$ ASME/SAE/ASEE Joint Propulsion Conference, Indianapolis, IN, June 27-29, 1994.

2. McBride, B.J. and Gordon, S., "Computer Program for Calculation of Complex Chemical Equilibrium Compositions and Applications," NASA-RP-1311, Lewis Research Center, Cleveland, Ohio, June 1996.

3. U. Goldberg, O. Peroomian, and S. Chakravarthy and B. Sekar "Validation of CFD++ Code Capability for Supersonic Combuster Flowfields," AIAA-97-3271, Seattle 1997.

4. Chakravarthy, S., Peroomian, O., "Some Internal Flow Applications of a Unified-Grid CFD Methodology," AIAA-96-2926, $32^{\text {nd }}$ AIAA/ASME/ASEE Joint Propulsion Conference \& Exhibit, Lake Buena Vista, FL, July 1996.

5. Batten, P., Leschziner, M.A., and Goldberg, U.C., "Average-state Jacobians and Implicit Methods for Compressible Viscous and Turbulent Flows," J. Computational Physics, Vol. 137, pp. 38-78, 1997.

6. Wang, Ten-See, Thermophysics Characterization of Kerosene combustion", Journal of Thermophysics and Heat Transfer, 0887-8722 vol.15 no.2, pp. 140-147, 2001

7. Wang, T, Mcconnaughey P., Warsi, S., Chen, Y., "CFD Assessment of the Pollutant Environment From RD-170 Propulsion System Testing”, Aerospace Environmental Technology Conference, p 25-47, 1995

8. Gardiner, W.C., "Gas-Phase Combustion Chemistry," second ed., Springer, New York, 2000.

9. Westbrook, C.K., "Chemical Kinetic Modeling of Higher Hydrocarbon Fuels," AIAA Journal, vol. 24, no. 12, pp. 20022009,1986

10. Chen, Y.S., Shang, H.M., and Liaw, P., "A fast Algorithm for Transient All-Speed Flows and Finite-Rate Chemistry," AIAA-96-4445, Space Programs and Technologies Conference, Huntsville, AL, September 1996.

11. Greenwood, T., Prozan, R., Ratliff, A., and Seymour, D., "Analysis of Liquid Engine Rocket Exhaust Plumes," Journal of Spacecraft and Rockets, 0022-4650, vol 8, no 2, pp. 123-128, 1971. 


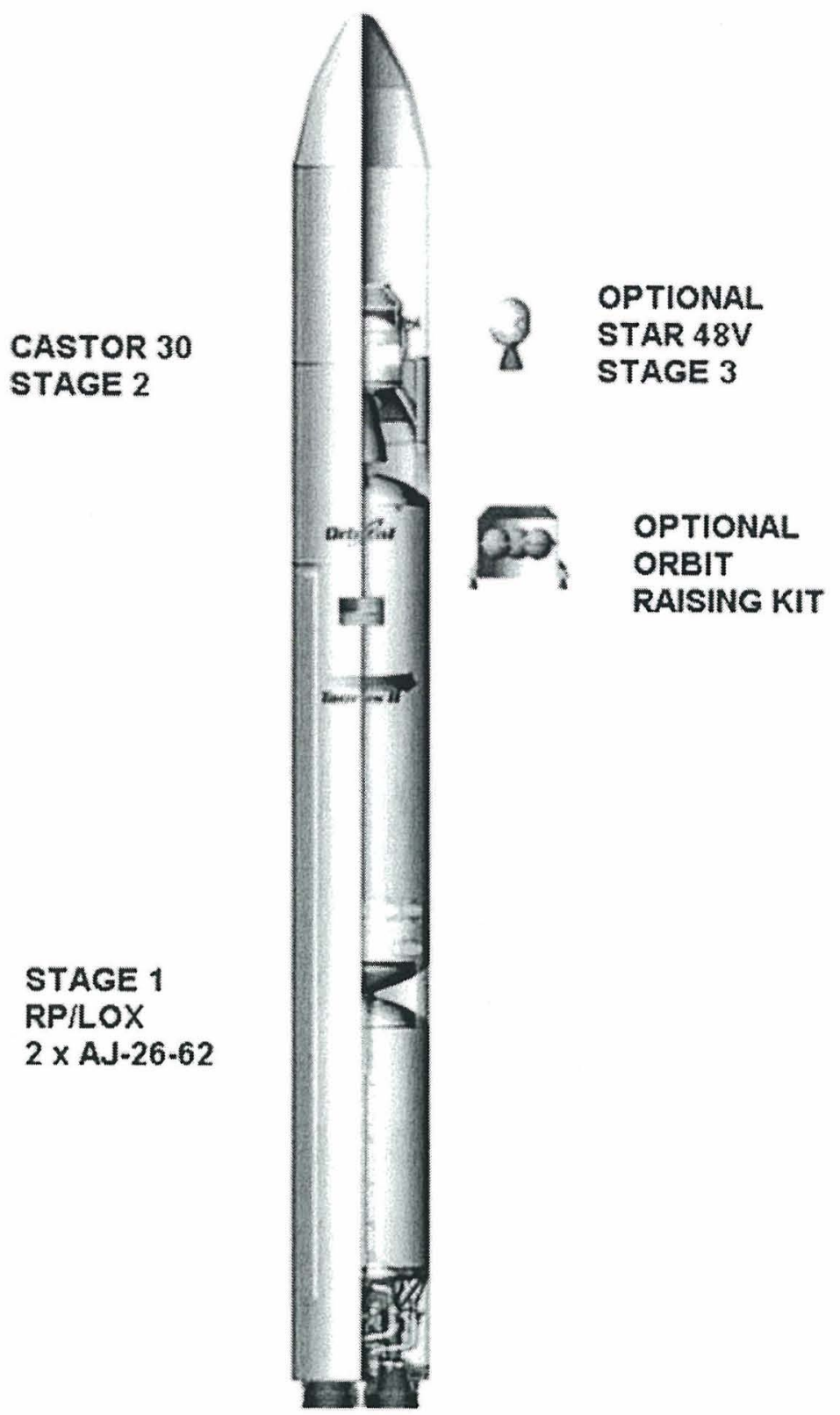

Fig. 1 Taurus-II Configuration

8

American Institute of Aeronautics and Astronautics 




Fig. 2 Stage 1 Test Configuration



Fig. 3 Computational Domain

9

American Institute of Aeronautics and Astronautics 


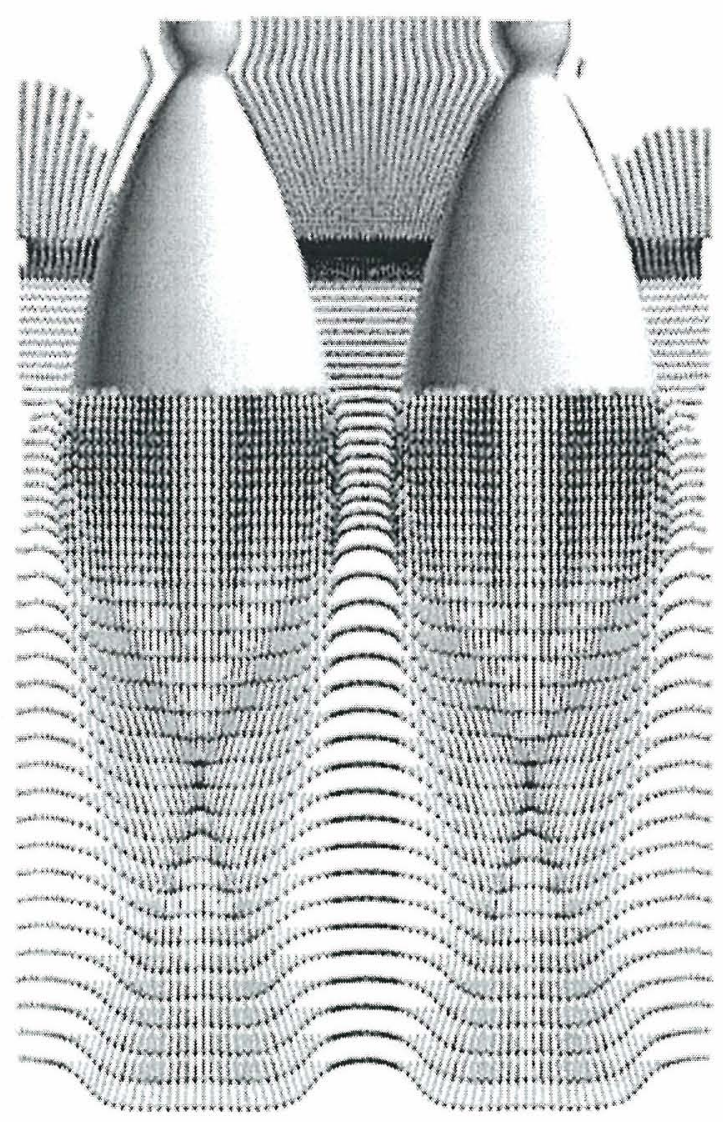

Fig. 4 Velocity vectors, single species

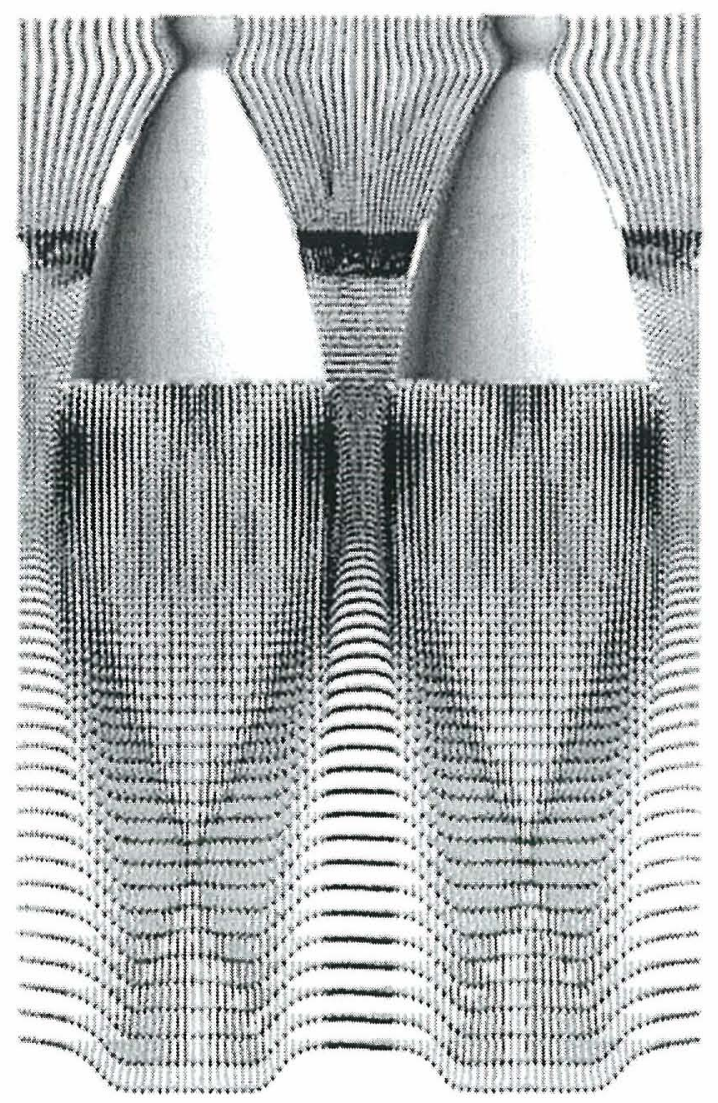

Fig. 5 Velocity vectors, multi species 


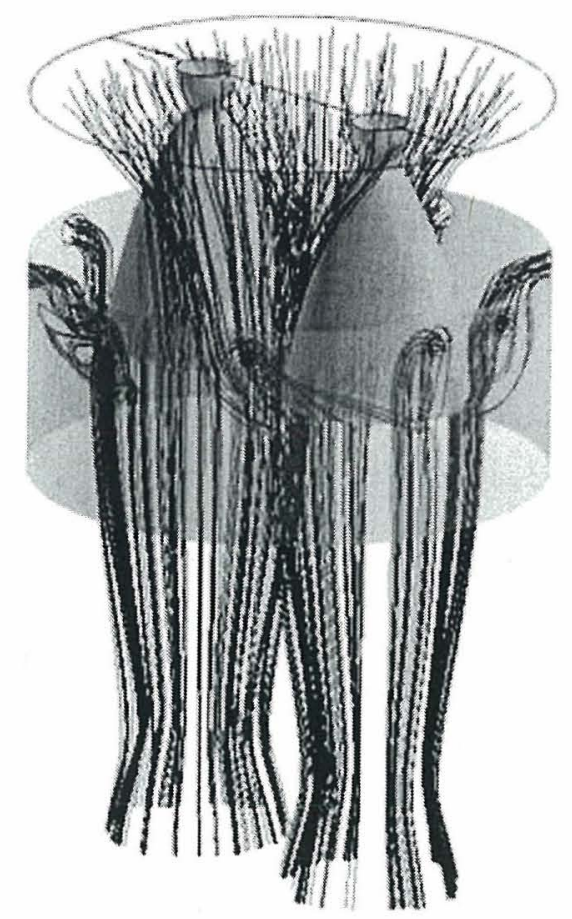

Fig. 6 Particle traces (single-species)

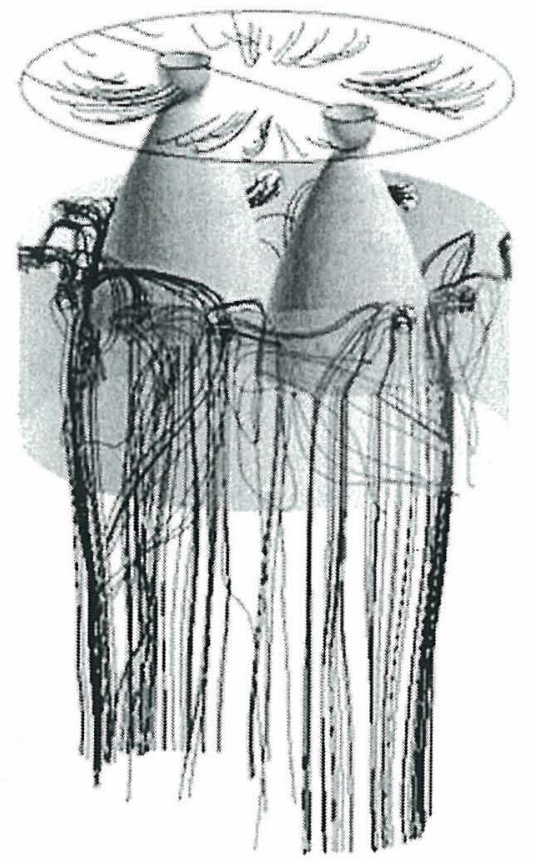

Fig. 7 Particle traces (multi-species) 


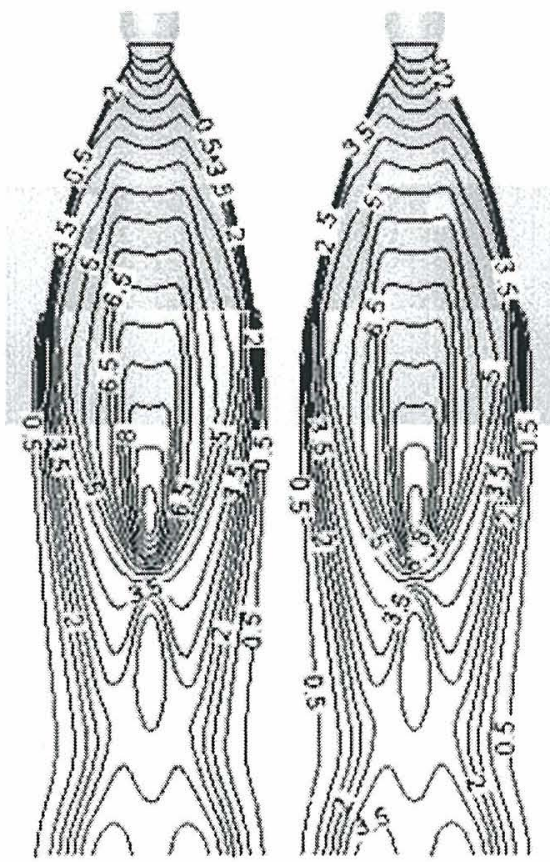

Fig. 8 Mach contours at the symmetry plane (single-species)

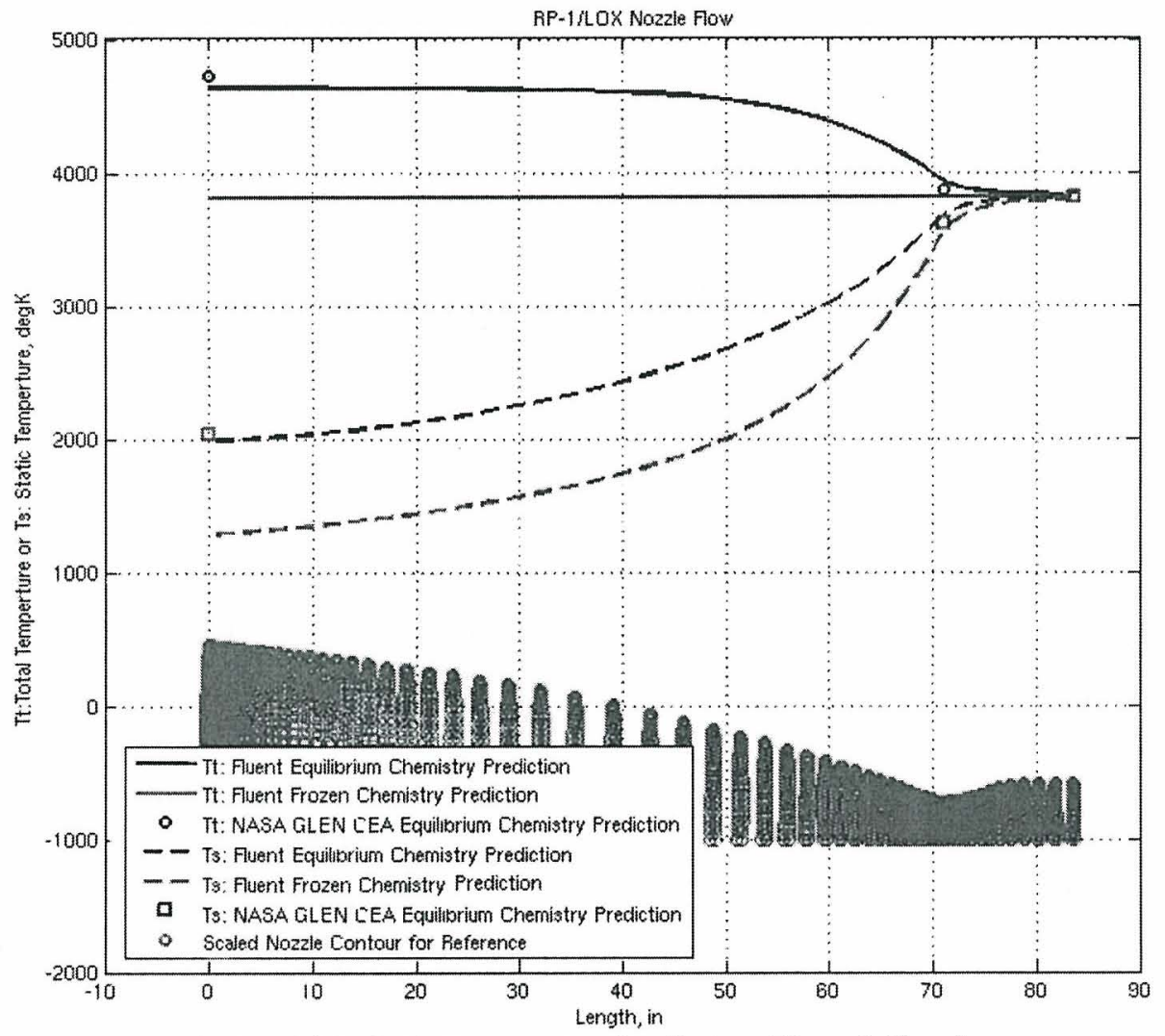

Fig 9 Total \& Static Temperature Predictions Through Nozzle

American Institute of Aeronautics and Astronautics 




Fig 10 Sonic velocity contours at the symmetry plane (multi-species)
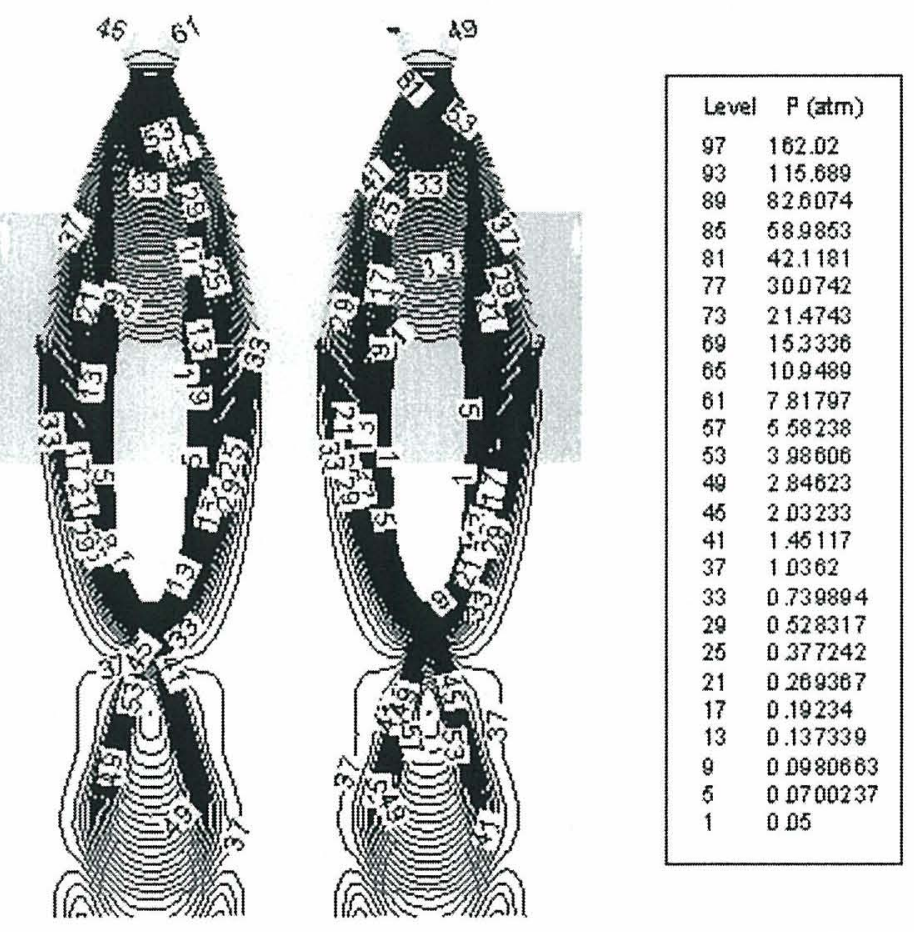

Fig 11 Pressure contours at the symmetry plane (single-species) 


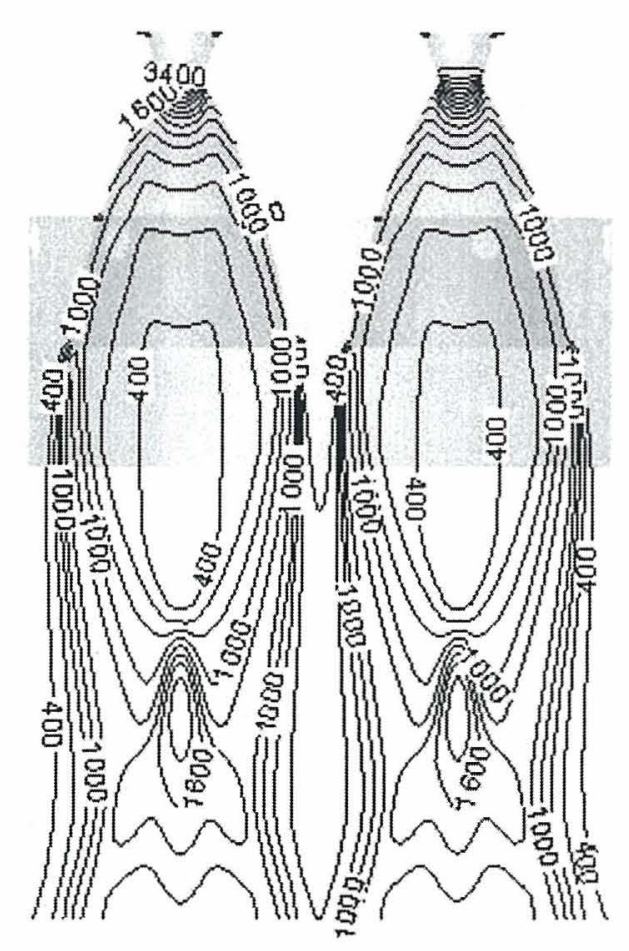

Fig 12 Temperature contours at the symmetry plane (single-species)



Fig 13 Mach number contours at the symmetry plane (multi-species) 


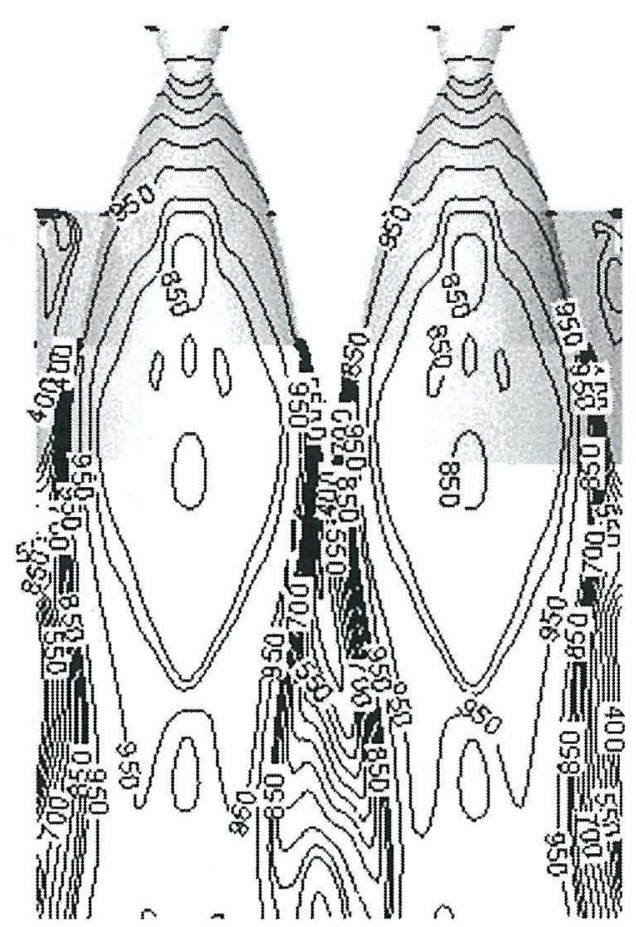

Fig 14 Sonic velocity contours at the symmetry plane (multi-species)

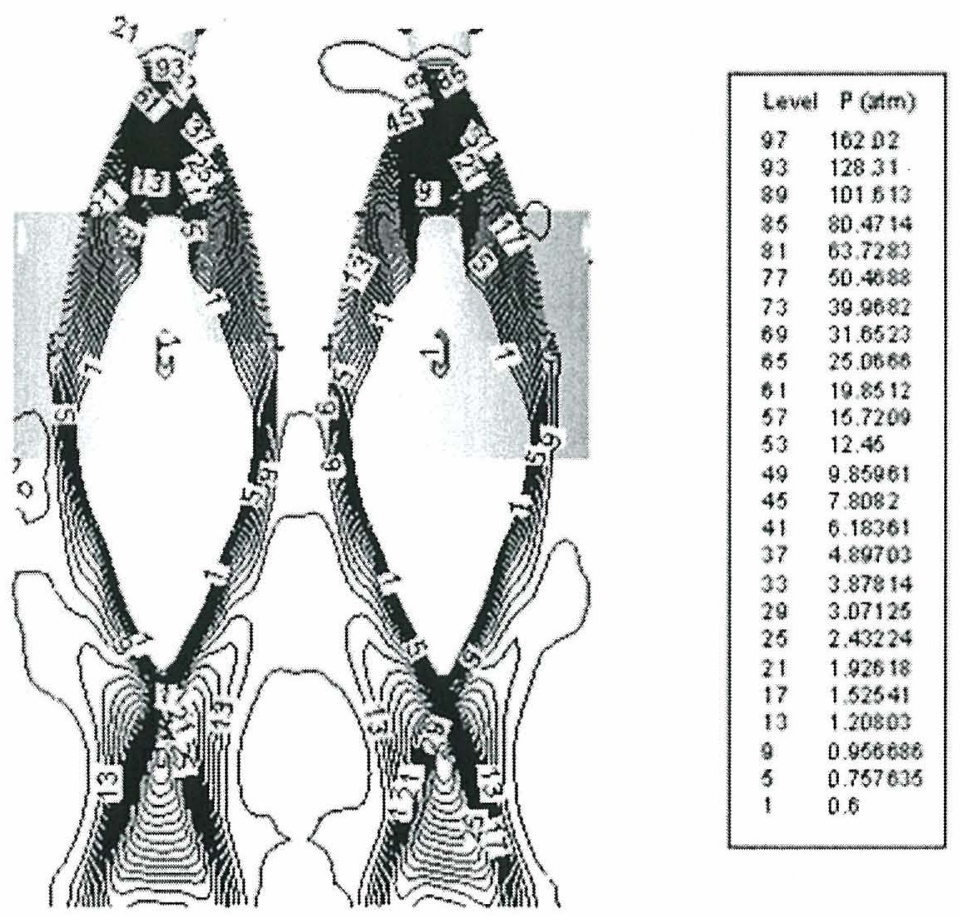

Fig 15 Pressure contours at the symmetry plane (multi-species) 


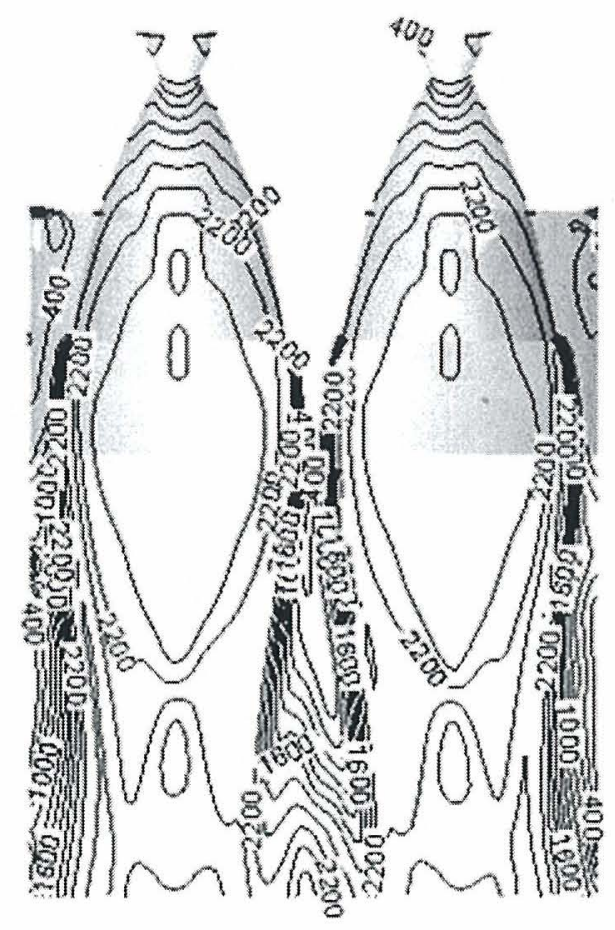

Fig 16 Temperature contours at the symmetry plane (multi-species)


Fig $17 \mathrm{CO} 2$ mole fraction at the symmetry plane

American Institute of Aeronautics and Astronautics 

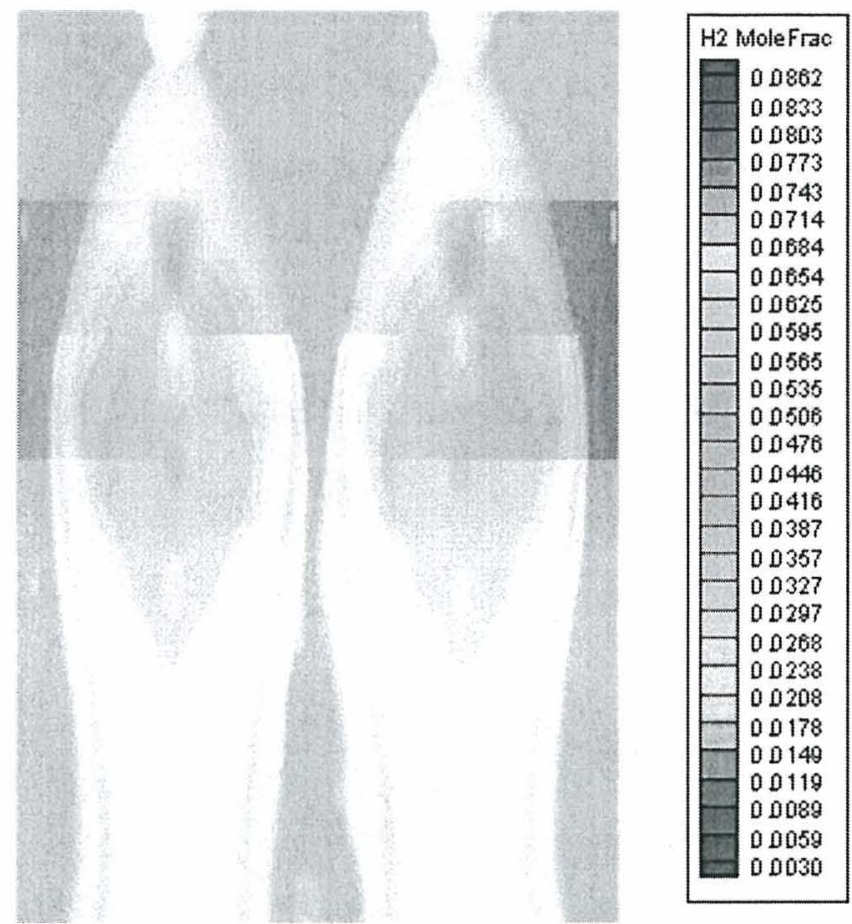

Fig $18 \mathrm{H} 2$ mole fraction at the symmetry plane



\begin{tabular}{|l|l|}
\hline H2 o MoleFrac \\
0.4160 \\
0.4017 \\
0.3873 \\
0.3730 \\
0.3586 \\
0.3443 \\
0.3299 \\
0.3156 \\
0.3012 \\
0.2869 \\
0.2726 \\
0.2582 \\
0.2439 \\
0.2295 \\
0.2152 \\
0.2008 \\
0.1865 \\
0.1721 \\
0.1578 \\
0.1434 \\
0.1291 \\
0.1148 \\
0.1004 \\
0.0861 \\
0.0717 \\
0.0574 \\
0.0430 \\
0.0287 \\
0.0143 \\
0.0000 \\
\hline
\end{tabular}

Fig $19 \mathrm{H} 2 \mathrm{O}$ mole fraction at the symmetry plane 



Fig $20 \mathrm{O} 2$ mole fraction at the symmetry plane

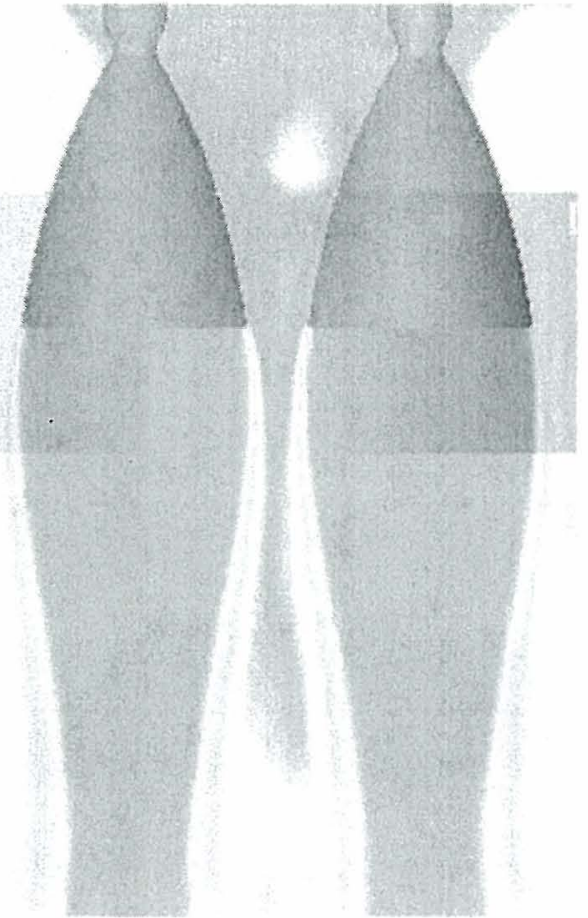

\begin{tabular}{|l|}
\hline N2 Mole Frac \\
0.9867 \\
0.9333 \\
0.9000 \\
0.8667 \\
0.8333 \\
0.8000 \\
0.7687 \\
0.7333 \\
0.7000 \\
0.6667 \\
0.6333 \\
0.6000 \\
0.5687 \\
0.5333 \\
0.5000 \\
0.4667 \\
0.4333 \\
0.4000 \\
0.3667 \\
0.3333 \\
0.3000 \\
0.2667 \\
0.2333 \\
0.2000 \\
0.1667 \\
0.1333 \\
0.1000 \\
0.0667 \\
0.0333 \\
\hline
\end{tabular}

Fig 21 N2 mole fraction at the symmetry plane 18

American Institute of Aeronautics and Astronautics 